\title{
Evidence of Pre-Synaptic Dopaminergic Deficit in a Patient with a Novel Progranulin Mutation Presenting with Atypical Parkinsonisr
}

\author{
Miryam Carecchio ${ }^{\mathrm{a}, 1, *}$, Dan \\ Cristoforo Comi ${ }^{\mathrm{a}}$, Emanuela

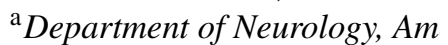

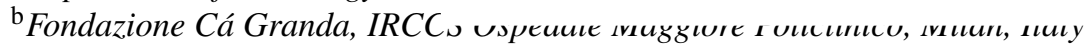

Handling Associate Editor: Annamaria Confaloni

\begin{abstract}
Parkinsonism can be the presenting feature of frontotemporal dementia due to Progranulin $(G R N)$ mutations or develop over the course of the disease, mimicking idiopathic Parkinson's disease or atypical parkinsonism. Here we report on a patient carrying a novel GRN mutation who presented with asymmetric parkinsonism and developed cognitive decline and language alterations two years later. Brain MRI showed mild asymmetric fronto-parietal atrophy. Single-photon emission computed tomography with ${ }^{123}$ ioflupane (DAT-Scan) demonstrated reduced tracer uptake in the left putamen. Larger studies are needed to clarify whether presynaptic dopaminergic deficit is present in all GRN mutation carriers or only in those with parkinsonism.
\end{abstract}

Keywords: Atypical, DAT-Scan, frontotemporal dementia, parkinsonism, progranulin

\section{INTRODUCTION}

Mutations in the Progranulin gene $(G R N)$ have been associated with various clinical phenotypes, the most frequent one being behavioral variant frontotemporal dementia (bvFTD), that accounts for about half of the cases $[1,2]$. However, even patients with no behavioral

\footnotetext{
${ }^{\dagger}$ This article is in memory of Professor Francesco Monaco, MD, 1946-2011.

${ }^{1}$ These authors contributed equally to this manuscript.

*Correspondence to: Miryam Carecchio, MD, Department of Neurology, Amedeo Avogadro University, Corso Mazzini, 18, 28100 Novara, Italy. Tel.: +390321 3733965; Fax: +390321 3733298; E-mail: mcarecchio@gmail.com.
}

or cognitive symptoms at onset and without a clearly autosomal dominant family history can be carriers of mutations in the GRN gene [3-5].

Parkinsonism can be observed in patients with $G R N$ mutations both at onset and over the course of the disease, sometimes resembling Parkinson's disease (PD) or atypical parkinsonism including Lewy body dementia (LBD), corticobasal degeneration (CBD), progressive supranuclear palsy (PSP), and multiple system atrophy (MSA) ([6-8]; see [2] for review). Interestingly, previous clinical and neuropathological studies suggested that parkinsonism may be more frequent in FTD patients with GRN mutations than in non-carriers $[9,10]$. 
Diagnosis of FTD caused by GRN mutations is based on clinical suspicion, low GRN plasma levels [11-13], and positive genetic testing; brain MRI can also provide important clues for an accurate diagnosis, showing asymmetrical frontal, temporal, and inferior parietal lobe atrophy in most cases [2].

\section{CASE REPORT}

A right-handed Italian man presented with asymmetric rest tremor of the right hand at age 51. His past medical history included blood hypertension and diabetes mellitus, both treated with oral drugs. There was no family history of any neurological or psychiatric disorders, and the patient had no children. He denied previous assumption of neuroleptics or exposure to toxic agents. Two years after the onset of symptoms, the tremor became more severe, interfering with everyday activities, and he started complain- ing of poor concentration, difficulties in calculation, and memory deficits. He came to our attention at age 53. Neurological examination showed hypomimic face, asymmetric jerky rest, postural non-re-emergent and action tremor in the right hand as well as mild bradykinesia on finger-tapping on the same side. He walked with stooped posture and reduced arm-swings on the right side; muscular tone was increased in the right arm with cogwheel rigidity in the elbow (See Supplementary Video). His language was poor, with stuttering and frequent paraphasias. Eye movement examination revealed slow initiation of saccades. Brain MRI showed bilateral fronto-temporal atrophy, slightly more prominent on the left side with periventricular subcortical hyperintensities on FLAIR sequences (Fig. 1). Accordingly, a perfusion SPECT displayed bilateral frontal hypoperfusion, more marked on the left side, with homolateral parieto-temporal hypoperfusion. Slow theta waves were visible on the left hemisphere on EEG. Cerebrospinal fluid biomarkers
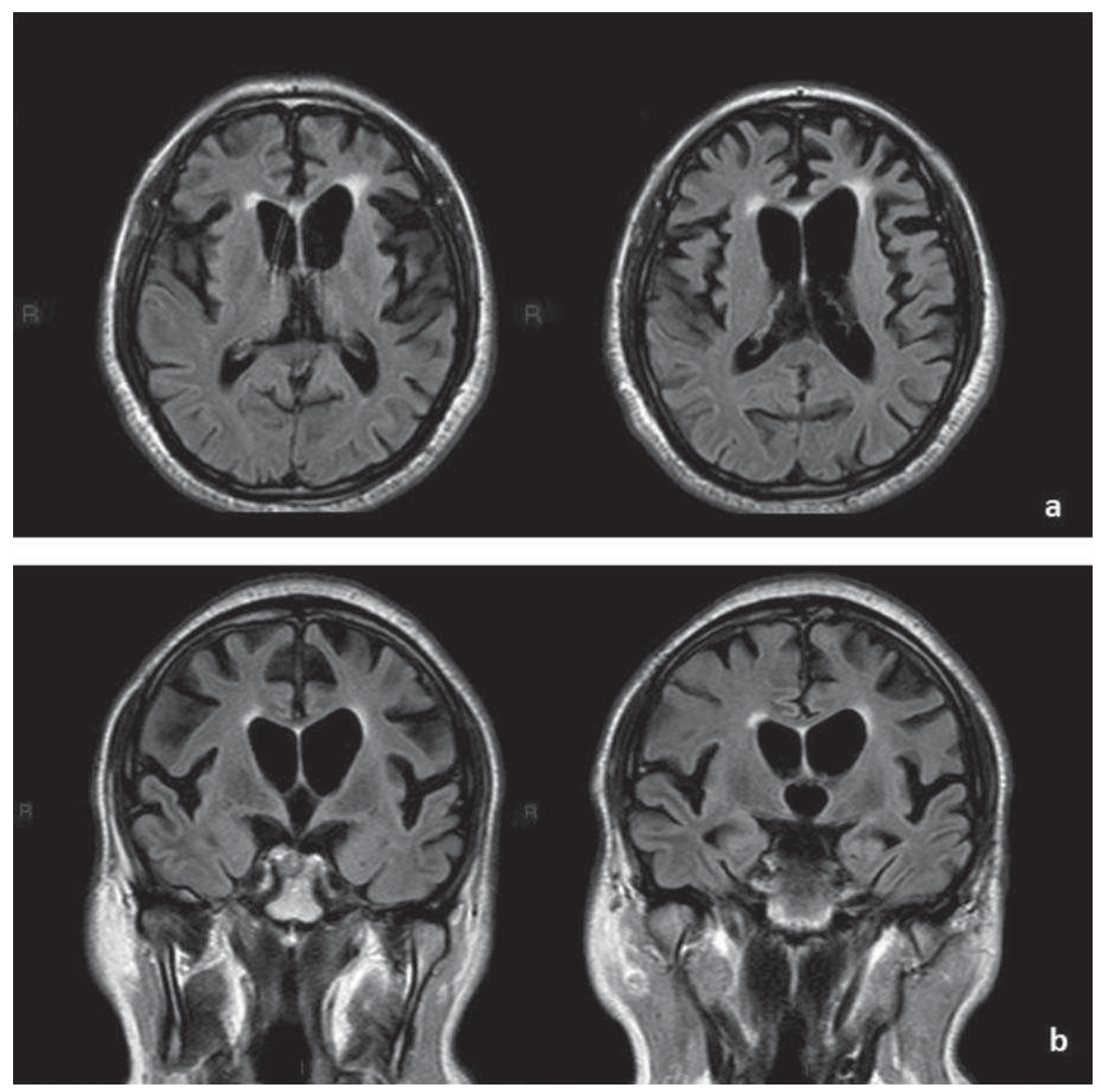

Fig. 1. Brain MRI (FLAIR sequences) demonstrating bilateral frontal and temporal atrophy, more marked on the left hemisphere; a) axial images; b) coronal images. 

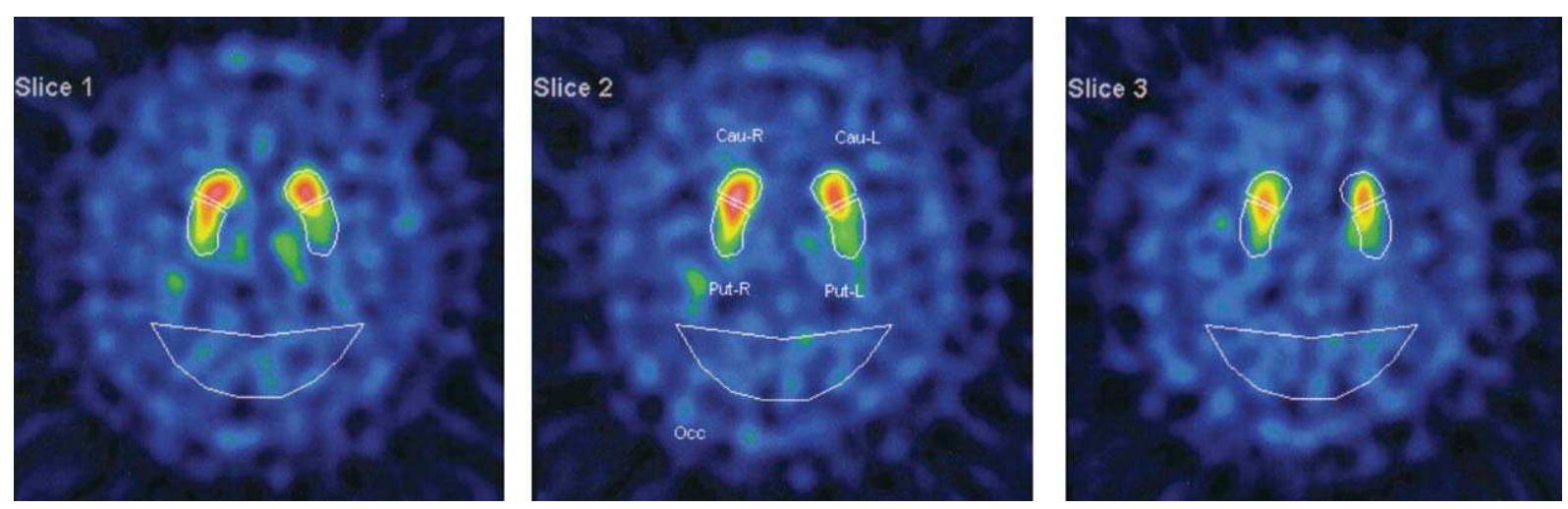

Fig. 2. DAT-Scan demonstrating reduced tracer uptake in the left putamen.

$\left(\mathrm{A} \beta_{42}\right.$, total tau, $\left.\mathrm{P}-181 \mathrm{tau}\right)$ were all in normal range. Formal neuropsychometry revealed a Mini-Mental State Exam score of 24/30, and language impairment with semantic deficits.

The presence of parkinsonism with cognitive impairment and language alterations, although without behavioral symptoms, raised the suspicion of FTD, supported by frontal and temporal atrophy on brain MRI. Given the relatively high prevalence of $G R N$ mutations in sporadic FTD cases as compared to MAPT mutations, we first assessed plasmatic Progranulin concentration, which resulted markedly decreased (13 pg/ml, normal values $>70 \mathrm{pg} / \mathrm{ml})$. Subsequently, $G R N$ sequencing revealed a novel variant in exon 9 (G387fs $25 \mathrm{X})$. To determine whether this was a pathogenic variant, the patient's mRNA was extracted from peripheral mononuclear blood cells and retrotranscribed to c-DNA. Subsequent sequencing showed a wild type profile, therefore confirming that the mutation leads to a premature stop codon with haploinsufficiency.

To further investigate the nature of parkinsonism, a SPECT with I ${ }^{123}$ ioflupane (DAT-Scan) was performed showing reduced tracer uptake in the left putamen, consistent with the patient's right-sided parkinsonism (Fig. 2).

Six months later, the patient presented behavioral changes with hypersexuality and verbal aggressiveness. Low doses of Quetiapine $(25 \mathrm{mg} /$ day) were started with good control of behavioral symptoms. Given the pre-synaptic nature of parkinsonism as showed by DAT-Scan, low doses of Levodopa/ Benserazide $(100 \mathrm{mg} /$ day $)$ were started, warning the patient about the potential development of behavioral sideeffects. Total daily dose was slowly increased up to $600 \mathrm{mg} /$ day with no benefit on rest tremor, bradyki- nesia, rigidity, and other parkinsonian signs; no side effects were observed.

The disease course has been progressive so far; on follow up one year after the diagnosis ( 3 years after the onset), the patient had developed overt dementia with apathy, severe language deficits with echolalia, urinary incontinence, and complete loss of independence in the activities of daily living. Parkinsonism has remained relatively stable over time.

\section{METHODS}

Cerebrospinal fluid (CSF) was obtained in polypropylene tubes by lumbar puncture at the L4/L5 interspace, centrifuged at $4{ }^{\circ} \mathrm{C}$, and stored at $\leq-30^{\circ} \mathrm{C}$ until analysis. $\mathrm{A} \beta_{42}$, total tau, and P-181 tau CSF levels were determined with human specific ELISA kits (Innogenetics). A $\beta_{42}$ and tau reference levels were considered according to Sjögren et al. [14]. Regarding P-tau, we considered as reference value the concentration suggested by the manufacturer's protocol $(<61 \mathrm{pg} / \mathrm{ml})$.

Plasma progranulin levels were evaluated with specific ELISA kits (Adipogene, Korea).

High-molecular weight DNA was isolated from whole blood using a Flexigene Kit (Qiagen, Hildren, Gemany), as described by the manufacturer. The amount of DNA for each sample was determined using a NanoDrop ND-3300 ${ }^{\circledR}$ Fluorospectrometer. DNA samples were aliquoted and stored at $-20^{\circ} \mathrm{C}$ until use. The entire open reading frame including the noncoding exon 0 and exon-intron boundaries of exons 1-12 of the GRN gene was sequenced in FTLD patients, using specific primers, as previously described [15]. Patient's consent was obtained to perform genetic analysis. 


\section{DISCUSSION}

GRN mutations are responsible for a significant number of sporadic and familial cases of FTD with variable clinical presentations. These include, as in our case, movement disorders mimicking PD or atypical parkinsonism [8, 16-19]. The patient reported herein first presented with asymmetric rest tremor, while mild cognitive deficits became evident only two years later, followed by behavioral changes. His initial symptoms at age 51 (mild asymmetric parkinsonism) were possibly consistent with PD, as no atypical additional signs or symptoms were detected at onset or in the first two years of the disease. However, formal neuropsychometry at age 53 as well as detailed neurological examination revealed language deficits and cognitive decline more severe than expected in a patient with PD complicated by PD dementia (PDD). In this context, abnormal DAT-Scan could have led to either a diagnosis of PDD or atypical parkinsonism, such as CBD.

Little is known about the pathogenesis of movement disorders in FTLD and large studies investigating the nature of parkinsonism in FTLD patients with or without GRN mutations are lacking. Neuropathological studies by Josephs et al. [9] showed that GRN positive patients display a more prominent degeneration of the substantia nigra and caudate nuclei as compared to $G R N$-negative FTD cases. Accordingly, we first provide evidence of pre-synaptic dopaminergic deficit in a GRN mutation carrier. Whether this is a mutation and/or phenotype-specific effect present only in a subset of subjects with FTD and parkinsonism or in specific $G R N$ mutations is yet to be determined with larger studies.

Parkinsonism in FTLD is generally poorly or not responsive to Levodopa $[11,16]$, similarly to most cases of atypical parkinsonism, although different degrees of clinical improvement after Levodopa administration have been reported $[5,13]$. In our case, extrapyramidal signs did not improve with Levodopa, although we cannot exclude that quetiapine partially reduced its effect being a dopamine-receptor blocking agent.

Alterations of dopamine synthesis along the nigrostriatal pathway due to degeneration of neurons of the substantia nigra is reflected by abnormal DAT-tracer uptake and has been demonstrated in various neurodegenerative disorders in which parkinsonism can be part of the clinical picture at different stages. These include SCA2, SCA 3, SCA6, and SCA17 [20-22], Cerebrotendinous Xanthomatosis [23], and early-onset dystonia-parkinsonism due to PLA2G6 mutations [24]; alterations of DAT-Scan have been shown in idiopathic REM sleep behavior disorder as well [25], and in fragile X-associated tremor ataxia syndrome [26]. Recently, O'Dowd and colleagues described a patient carrying a pathogenic C9Orf72 hexanucleotide expansion presenting with a complex phenotype including amyotrophic lateral sclerosis, FTD, and parkinsonism who also showed abnormal DAT-Scan [27].

However, extensive studies investigating reduced dopamine synthesis in FTLD have not been performed yet. Here we show for the first time that a pre-synaptic dopamine deficit is present in a patient with FTD due to GRN mutations presenting with asymmetric parkinsonism, thus adding another possible differential to the list of atypical parkinsonism with abnormal DAT-Scan (MSA, PSP, CBD, LBD) and providing a rationale for the treatment of movement disorders in FTD with parkinsonism, despite no studies to assess the effectiveness of Levodopa or dopamine-agonists in FTD with parkinsonism are available and our case did not show a significant improvement on LD treatment.

In conclusion, we describe a novel GRN mutation leading to haploinsufficiency, presenting with atypical parkinsonism, language dysfunction, and a rapid progression to full blown dementia. Furthermore, we describe for the first time alterations of DAT-Scan in a case of FTD due to GRN mutations. This description enlarges the spectrum of known GRN mutations and related clinical phenotypes.

\section{DISCLOSURE STATEMENT}

Authors' disclosures available online (http://www.jalz.com/disclosures/view.php?id=1907).

\section{SUPPLEMENTARY MATERIAL}

A supplementary video is available in the electronic version of this article: http://dx.doi.org/10.3233/JAD131151 .

\section{REFERENCES}

[1] Johnson JK, Diehl J, Mendez MF, Neuhaus J, Shapira JS, Forman M, Chute DJ, Roberson ED, Pace-Savitsky C, Neumann M, Chow TW, Rosen HJ, Forstl H, Kurz A, Miller BL (2005) Frontotemporal lobar degeneration: Demographic characteristics of 353 patients. Arch Neurol 62, 925-930.

[2] Seelaar H, Rohrer JD, Pijnenburg YA, Fox NC, van Swieten JC (2011) Clinical, genetic and pathological heterogeneity of frontotemporal dementia: A review. J Neurol Neurosurg Psychiatry 82, 476-486. 
[3] Pickering-Brown SM, Baker M, Gass J, Boeve BF, Loy CT, Brooks WS, Mackenzie IR, Martins RN, Kwok JB, Halliday GM, Kril J, Schofield PR, Mann DM, Hutton M (2006) Mutations in progranulin explain atypical phenotypes with variants in MAPT. Brain 129, 3124-3126.

[4] Le Ber I, van der Zee J, Hannequin D, Gijselinck I, Campion D, Puel M, Laquerrière A, De Pooter T, Camuzat A, Van den Broeck M, Dubois B, Sellal F, Lacomblez L, Vercelletto M, Thomas-Antérion C, Michel BF, Golfier V, Didic M, Salachas F, Duyckaerts C, Cruts M, Verpillat P, Van Broeckhoven C, Brice A, French Research Network on FTD/FTD-MND (2007) Progranulin null mutations in both sporadic and familial frontotemporal dementia. Hum Mutat 28, 846-855.

[5] Kelley BJ, Haidar W, Boeve BF, Baker M, Graff-Radford NR, Krefft T, Frank AR, Jack CR Jr, Shiung M, Knopman DS, Josephs KA, Parashos SA, Rademakers R, Hutton M, Pickering-Brown S, Adamson J, Kuntz KM, Dickson DW, Parisi JE, Smith GE, Ivnik RJ, Petersen RC (2009) Prominent phenotypic variability associated with mutations in Progranulin. Neurobiol Aging 30, 739-751.

[6] van Swieten JC, Heutink P (2008) Mutations in progranulin (GRN) within the spectrum of clinical and pathological phenotypes of frontotemporal dementia. Lancet Neurol 7, 965-974.

[7] Le Ber I, Camuzat A, Hannequin D, Pasquier F, Guedj E, Rovelet-Lecrux A, Hahn-Barma V, van der Zee J, Clot F, Bakchine S, Puel M, Ghanim M, Lacomblez L, Mikol J, Deramecourt V, Lejeune P, de la Sayette V, Belliard S, Vercelletto M, Meyrignac C, Van Broeckhoven C, Lambert JC, Verpillat P, Campion D, Habert MO, Dubois B, Brice A, French research network on FTD/FTD-MND (2008) Phenotype variability in progranulin mutation carriers: A clinical, neuropsychological, imaging and genetic study. Brain 131, 732-746.

[8] Yu C, Bird TD, Bekris LM, Montine TJ, Leverenz JB, Steinbart E, Galloway NM, Feldman H, Woltjer R, Miller CA, Wood EM, Grossman M, McCluskey L, Clark CM, Neumann M, Danek A, Galasko DR, Arnold SE, Chen-Plotkin A, Karydas A, Miller BL, Trojanowski JQ, Lee VM, Schellenberg GD, Van Deerlin VM (2010) The spectrum of mutations in progranulin. A collaborative study screening 545 cases of neurodegeneration. Arch Neurol 67, 161-170.

[9] Josephs KA, Ahmed Z, Katsuse O, Parisi JF, Boeve BF, Knopman DS, Petersen RC, Davies P, Duara R, Graff-Radford NR, Uitti RJ, Rademakers R, Adamson J, Baker M, Hutton ML, Dickson DW (2007) Neuropathologic features of frontotemporal lobar degeneration with ubiquitin-positive inclusions with progranulin gene (PGRN) mutations. J Neuropathol Exp Neurol 66, 142-151.

[10] Beck J, Rohrer JD, Campbell T, Isaacs A, Morrison KE, Goodall EF, Warrington EK, Stevens J, Revesz T, Holton J, Al-Sarraj S, King A, Scahill R, Warren JD, Fox NC, Rossor MN, Collinge J, Mead S (2008) A distinct clinical, neuropsychological and radiological phenotype is associated with progranulin gene mutations in a large UK series. Brain 131, 706-720.

[11] Ghidoni R, Benussi L, Glionna M, Franzoni M, Binetti G (2008) Low plasma progranulin levels predict progranulin mutations in frontotemporal lobar degeneration. Neurology 71, 1235-1239.

[12] Finch N, Baker M, Crook R, Swanson K, Kuntz K, Surtees R, Bisceglio G, Rovelet-Lecrux A, Boeve B, Petersen RC, Dickson DW, Younkin SG, Deramecourt V, Crook J, GraffRadford NR, Rademakers R (2009) Plasma progranulin levels predict progranulin mutation status in frontotemporal demen- tia patients and asymptomatic family members. Brain 132, 583-591.

[13] Carecchio M, Fenoglio C, De Riz M, Guidi I, Comi C, Cortini F, Venturelli E, Restelli I, Cantoni C, Bresolin N, Monaco F, Scarpini E, Galimberti D (2009) Progranulin plasma levels as potential biomarker for the identification of GRN deletion carriers. A case with atypical onset as clinical amnestic Mild Cognitive Impairment converted to Alzheimer's disease. J Neurol Sci 287, 291-293.

[14] Sjögren M, Vanderstichele H, Agren H, Zachrisson O, Edsbagge M, Wikkels $\varnothing$ C, Skoog I, Wallin A, Wahlund LO, Marcusson J, Nägga K, Andreasen N, Davidsson P, Vanmechelen E, Blennow K (2001) Tau and Abeta42 in cerebrospinal fluid from healthy adults $21-93$ years of age: Establishment of reference values. Clin Chem 47, 1776-1781.

[15] Gass J, Cannon A, Mackenzie IR, Boeve B, Baker M, Adamson J, Crook R, Melquist S, Kuntz K, Petersen R, Josephs K, Pickering-Brown SM, Graff-Radford N, Uitti R, Dickson D, Wszolek Z, Gonzalez J, Beach TG, Bigio E, Johnson N, Weintraub S, Mesulam M, White CL, 3rd, Woodruff B, Caselli R, Hsiung GY, Feldman H, Knopman D, Hutton M, Rademakers R (2006) Mutations in progranulin are a major cause of ubiquitin-positive frontotemporal lobar degeneration. Hum Mol Genet 15, 2988-3001.

[16] Boeve BF, Baker M, Dickson DW, Parisi JE, Giannini C, Josephs KA, Hutton M, Pickering-Brown SM, Rademakers R, Tang-Wai D, Jack CR Jr, Kantarci K, Shiung MM, Golde T, Smith GE, Geda YE, Knopman DS, Petersen RC (2006) Frontotemporal dementia and parkinsonism associated with the IVS1+ 1G-> A mutation in progranulin: A clinicopathologic study. Brain 129, 3103-3114.

[17] Rohrer JD, Beck J, Warren JD, King A, Al Sarraj S, Holton J, Revesz T, Collinge J, Mead S (2009) Corticobasal syndrome associated with a novel 1048_1049insG progranulin mutation. J Neurol Neurosurg Psychiatry 80, 1297-1298.

[18] Benussi L, Ghidoni R, Pegoiani E, Moretti DV, Zanetti O, Binetti G (2009) Progranulin Leu271LeufsX10 is one of the most common FTLD and CBS associated mutations worldwide. Neurobiol Dis 33, 379-385.

[19] Tremolizzo L, Bertola F, Casati G, Piperno A, Ferrarese C, Appollonio I (2011) Progressive supranuclear palsy-like phenotype caused by progranulin p. Thr $272 \mathrm{fs}$ mutation. Mov Disord 26, 1964-1966.

[20] Kim JY, Kim SY, Kim JM, Kim YK, Yoon KY, Kim JY, Lee BC, Kim JS, Paek SH, Park SS, Kim SE, Jeon BS (2009) Spinocerebellar ataxia type 17 mutation as a causative and susceptibility gene in parkinsonism. Neurology 72, 1385-1389.

[21] Kim JM, Lee JY, Kim HJ, Kim JS, Kim YK, Park SS, Kim SE, Jeon BS (2010) The wide clinical spectrum and nigrostriatal dopaminergic damage in spinocerebellar ataxia type 6 . J Neurol Neurosurg Psychiatry 81, 529-532.

[22] Yun JY, Lee WW, Kim HJ, Kim JS, Kim JM, Kim HJ, Kim SY, Kim JY, Park SS, Kim YK, Kim SE, Jeon BS (2011) Relative contribution of SCA2, SCA3 and SCA17 in Korean patients with parkinsonism and ataxia. Parkinsonism Relat Disord 17, 338-342.

[23] Su CS, Chang WN, Huang SH, Lui CC, Pan TL, Lu $\mathrm{CH}$, Chuang YC, Huang CR, Tsai NW, Hsieh MJ, Chang CC (2010) Cerebrotendinous xanthomatosis patients with and without parkinsonism: Clinical characteristics and neuroimaging findings. Mov Disord 25, 452-458.

[24] Shi CH, Tang BS, Wang L, Lv ZY, Wang J, Luo LZ, Shen L, Jiang H, Yan XX, Pan Q, Xia K, Guo JF (2011) PLA2G6 gene mutation in autosomal recessive early-onset parkinsonism in a Chinese cohort. Neurology 77, 75-81. 
[25] Iranzo A, Valldeoriola F, Lomeña F, Molinuevo JL, Serradell M, Salamero M, Cot A, Ros D, Pavía J, Santamaria J, Tolosa E (2011) Serial dopamine transporter imaging of nigrostriatal function in patients with idiopathic rapid-eye-movement sleep behaviour disorder: A prospective study. Lancet Neurol 10, 797-780.

[26] Madeo G, Alemseged F, Di Pietro B, Schillaci O, Pisani A (2013) Early abnormalities in 123I-ioflupane (DaTSCAN) imaging in the fragile $\mathrm{X}$-associated tremor ataxia syndrome (FXTAS): A case report. Neurol Sci 34, 1475-1477.

[27] O’Dowd S, Curtin D, Waite AJ, Roberts K, Pender N, Reid V, O'Connell M, Williams NM, Morris HR, Traynor BJ, Lynch $\mathrm{T}$ (2012) C9ORF72 expansion in amyotrophic lateral sclerosis/frontotemporal dementia alsocauses parkinsonism. Mov Disord 27, 1072-1074. 